\title{
LIGHTWEIGHT IT AS A NEW ANALYTICAL LENS FOR DIGITALIZATION OF NGOS
}

\author{
Marie-E. Godefroid \\ Universität Siegen, Kohlbettstraße 15, 57072 Siegen, Germany
}

\begin{abstract}
While digitalization remains high on the agenda of most private sector organizations, many non-governmental organizations (NGOs) still struggle, due to budget constraints (Merkel et al. 2007). A concept that might be helpful in this context is lightweight IT. It describes "a socio-technical knowledge regime, driven by competent users' need for solutions, enabled by the consumerization of digital technology, and realized through innovation processes" (Bygstad 2017). By building on existing solutions and focusing on the user, NGOs might circumvent high IT spending and sub-optimal IT solutions that do not fit users' needs. A use case analysis along the NGO value chain shows that $\sim 1 / 3$ of the use cases identified from literature already represent lightweight IT examples. Nonetheless, certain lightweight IT solutions successfully deployed in the private sector like RPA do not appear at all, leaving room for future exploration and improvement.
\end{abstract}

\section{KEYWORDS}

Lightweight IT, Digitalization, Automation, Social Sector, NGO, Non-Governmental Organization

\section{INTRODUCTION}

There is significant pressure on NGOs to reduce administrative costs as donors prefer their contributions to reach program participants directly (Burkart et al. 2018). One possible means to achieve this cost reduction is digital technologies, as these can offer cost efficiencies (Kotoba 2017). But NGOs' information technology (IT) departments typically have very constrained budgets and lack the funds to invest lavishly into digitalizing operations (Merkel et al. 2007).

One way to solve this conflict between a growing need to digitalize and tightly constrained budgets could be lightweight IT: It describes an IT knowledge regime that can be driven from outside of the IT department and focuses on innovation and users' needs (Bygstad 2017). A knowledge regime is understood to include "the network of key actor groups (such as IT professionals, users, vendors), work practices, certain technologies and the shared knowledge on the appropriate development and use." (Bygstad 2017, p. 181) The aspect that it is usually 
implemented with cheap technology and requires less specialized IT skills should make it interesting for NGOs with their constrained budgets (Merkel et al. 2007). At the same time, it could also be interesting in volatile NGO contexts like disaster relief because solutions can be developed in a very short time and fully adapted to user needs (Bygstad 2017).

This paper, therefore, takes a closer look at existing case studies of different technology use cases in the NGO context. So far, there is no current literature review on NGOs and automation, digitalization, or just technology for that matter. Also, there is no overview of different technology use cases along the value chain. And finally, there is no transparency on how established lightweight technologies are already in the NGO context.

However, such an overview would be helpful for practitioners to learn from other organizations as well as to understand underlying systematics and manage strategies accordingly. For research, such an overview would be helpful as it allows the identification of avenues for further research and a consolidated view of the existing knowledge. Alone the diverse set of keywords used in publications in this context makes it hard for researchers to collect all relevant knowledge. Therefore, this research aims to close the identified gap by answering two research questions:

- RQ1: Which use cases for IT have researchers documented along the NGOs' value chain?

- $\quad$ RQ2: Are NGO's using more lightweight or more heavyweight solutions, and is there an equal distribution along the value chain?

This paper is structured as follows: The background section explains the lightweight IT concept in more detail. The third section describes the method, and the subsequent section presents the findings along the NGO value chain. The final section discusses the results and limitations and identifies further research opportunities.

\section{BACKGROUND}

\subsection{Lightweight IT}

This paper makes use of the lightweight and heavyweight IT concept first introduced by Bygstad in 2015. He derived his concepts from a series of observations in the Norwegian healthcare sector. Still, the distinction he makes also applies to IT in other disciplines, and researchers have already successfully transferred it to other sectors (Lacity and Willcocks 2016). He defined these concepts as follows: "Heavyweight IT is the traditional systems and databases, which are becoming more sophisticated and expensive through advanced integration. Lightweight IT is the new paradigm of mobile apps, sensors, and bring-your-own-device, also called consumerisation or Internet-of-Things." (Bygstad 2015, p. 181) Table 1 shows a systematic comparison of the two knowledge regimes along with relevant attributes.

Bygstad (2017) builds here on several active discourses in the information systems community: Bring-your-own-device describes the phenomenon that employees bring their own devices, e.g., smartphones to work want to use them for work purposes and thereby force IT departments to incorporate these into their overall technological landscape (Niehaves et al. 2012). Consumerization refers to the rising expectations of employees regarding easy-to-use and powerful IT solutions in their workforce because they are increasingly used to these from the consumer market (Harris et al. 2012). Finally, the internet-of-things is the growing network 
IADIS International Journal on Computer Science and Information Systems

of interconnected everyday objects that offer new use cases for IT as devices can communicate with humans and each other. Such use cases can, for example, be part of improved supply chains (Haddud et al. 2017).

Table 1. Heavyweight and lightweight IT (Bygstad 2017, p. 182)

\begin{tabular}{|c|c|c|}
\hline & Heavyweight IT & Lightweight IT \\
\hline & $\begin{array}{l}\text { A knowledge regime, driven by } \\
\text { IT professionals, enabled by } \\
\text { systematic specification and } \\
\text { proven digital technology and } \\
\text { realized through software } \\
\text { engineering. }\end{array}$ & $\begin{array}{l}\text { A knowledge regime, driven by } \\
\text { competent users' need for } \\
\text { solutions, enabled by the } \\
\text { consumerization of digital } \\
\text { technology and realized through } \\
\text { innovation processes }\end{array}$ \\
\hline & Heavyweight IT & Lightweight IT \\
\hline Profile & $\begin{array}{l}\text { Backend: Supporting } \\
\text { documentation of work }\end{array}$ & $\begin{array}{lll}\text { Frontend: } & \text { Supporting } & \text { work } \\
\text { processes } & & \\
\end{array}$ \\
\hline Owner & IT department & Process support, apps, BI \\
\hline Systems & Transaction systems & $\begin{array}{l}\text { Tablets, electronic whiteboards, } \\
\text { mobile phones }\end{array}$ \\
\hline Technology & $\begin{array}{l}\text { PCs, servers, databases, } \\
\text { integration technology }\end{array}$ & $\begin{array}{l}\text { Tablets, electronic whiteboards, } \\
\text { mobile phones }\end{array}$ \\
\hline IT architecture & $\begin{array}{l}\text { Fully integrated solutions, } \\
\text { centralized or distributed }\end{array}$ & $\begin{array}{l}\text { Non-invasive solutions, } \\
\text { frequently meshworks } \\
\text { (heterogeneous networks) }\end{array}$ \\
\hline $\begin{array}{l}\text { Development } \\
\text { Culture }\end{array}$ & Systematics, quality, security & Innovation, experimentation \\
\hline Problems & $\begin{array}{l}\text { Increasing complexity, rising } \\
\text { costs }\end{array}$ & Isolated gadgets, security \\
\hline Discourse & Software engineering & Business and practice innovation \\
\hline
\end{tabular}

Lightweight IT is especially interesting as it enables innovation due to three main characteristics:

- Usability and implementation speed allow for a fast introduction of the new systems - also based on the ability to bypass the existing infrastructure.

- Availability of the solutions on the market and vendors' ability to support pilots and implementations in an agile way, including experimenting, prototyping, and testing.

- Modular structure and layered architecture allow for a loose coupling to other system components (Øvrelid 2018).

In the context of NGOs, researchers have not yet studied the lightweight IT concept. But this does not mean that lightweight IT technologies are not already in use in NGOs or the social sector at large. Nonetheless, this analytical lens could be helpful to drive innovation and put relevant governance models that leave more room for lightweight IT into place (Bygstad and Iden 2017). 


\subsection{The NGO Value Chain}

The first step of this analysis was identifying a suitable NGO value chain to provide a frame of reference to analyze the use of lightweight IT by NGOs. In the tradition of the general business value chain introduced by Porter (1985), the aim was to find a representation of the most important primary and supporting activities of the operations of an NGO (Porter 1985). But to the best of the authors' efforts, no such value chain, process, or reference model could be identified in peer-reviewed literature - a keyword-based search with related search terms on Google Scholar returned no relevant results. Therefore, in the following, the NGO reference model is used. Practitioners developed this reference model in the wake of an NGO architecture discussion that started in 2014 with the first Enterprise Architecture Workshops held by the Nethope foundation. Practitioners from Save the Children, Water Aid, and SOS Children villages - three large NGOs - primarily developed this model, and seven further organizations endorsed it (Snow et al. 2016).

The NGO reference model was published in 2016 and describes four primary and six enabling or crosscutting activities. The primary activities are Programme Design, Fundraising, Fund Management, and Programme Delivery. Programme Design describes activities that shape a possible intervention and bring relevant stakeholders on board. Fundraising details activities to acquire the relevant resources and engage donors and sponsors. Fund management is about activities that allow for matching of funds and programmes and monitoring and reporting to stakeholders. Programme Delivery finally comprises all activities pertaining to a concrete programme, from the setup and implementation of controlling and monitoring efforts on the ground to evaluations and properly ending the programme (Snow et al. 2016).

The NGO reference model defines six enabling or crosscutting support activities in addition to the primary activities: Organizational Management \& Governance, Knowledge Management, Supply Chain Management, Finance, Human Resource Management, and Information Technology (Snow et al. 2016).

\section{METHOD}

This research followed two steps: First, we conducted a literature search for relevant case studies. Here, we tried to identify relevant publications from peer-reviewed literature. Second, we analyzed these publications through the lightweight IT lens to identify use cases along the NGO value chain. 


\begin{tabular}{|c|c|l|l|l|}
\hline 1 & Process & \multicolumn{2}{l|}{ Sequential } & Iterative \\
\hline 2 & Sources & Citation indexing services & Bibliographic databases & Publications \\
\hline 3 & Coverage & Comprehensive & Representative & Seminal works \\
\hline 4 & Techniques & Keyword search & Backward search & Forward search \\
\hline
\end{tabular}

Figure 1. Method for the literature review following vom Brocke et al. (2015)

We conducted a literature search for relevant case studies. Following vom Brocke et al. (2015), we systematically defined the search's scope: The approach was iterative as relevant results led to additional search terms and publications (vom Brocke et al. 2015). We searched Google Scholar, a citation indexing service. The coverage of the search aimed to be representative, i.e., multiple publications have looked at the use of social media by NGOs (Halpin et al. 2020; Lee 2018; Lai and Fu 2021; Seo and Vu 2020; Zhou and Pan 2016), but in the following, we only cite the first exploration of this use case as a representative example (Zhou and Pan 2016).

The search was keyword-based, focusing on the three different aspects: general IT, social sector, and lightweight IT terms. A search string was build-out of the combination of two-term groups and searched on Google Scholar and Semantic Scholar. As soon as three consecutive result pages did not contain relevant results, we ended the search, and we searched a new combination of terms.

- General IT terms: digitalization, automation, information systems, IS, information technology, IT, information and communication technology, ICT

- Social sector terms: Non-governmental organization, NGO, Nonprofit organization, NPO, social sector, a voluntary association

- Specific lightweight technologies as mentioned in the literature (Bygstad 2017): lightweight IT, frontend, process support, workflow management, app, application, tablet, electronic whiteboard, mobile technology, BI, business intelligence, IoT, Internet of Things, RPA, robotic process automation

A backward search was conducted as part of the iterative process once we identified a suitable publication. In the second step, the technology solutions discussed were classified as heavyweight or lightweight IT. We carefully examined the case studies for all mentions of aspects regarding the distinguishing criteria described by Bygstad, and classification was made (Bygstad 2017). On this basis, We determined the degree of the use of lightweight along the NGO value chain.

\section{FINDINGS}

Regarding the use of information and communication technology (ICT)/digitalization /automation (use of terms is not consistent in the literature) for NGOs, the scope in the literature varies quite extensively from the introduction of full-stack solutions like Service Now, including 
tablet computers at the Bruderhaus Diakonie (Müller et al. 2019) to the use of social media of Chinese NGOs (Zhou and Pan 2016).

While analyzing the identified use cases, we could not find any use case in the Programme Design phase. The reason for that could be that Programme Design is a very NGO-specific task. To date, practitioners have not yet developed tailored solutions for this and therefore it does not appear in research. As such, we focus on the last three steps in the following and discuss 14 use cases of information technology in Fundraising, Fund Management, and Programme Delivery - see figure 2 .

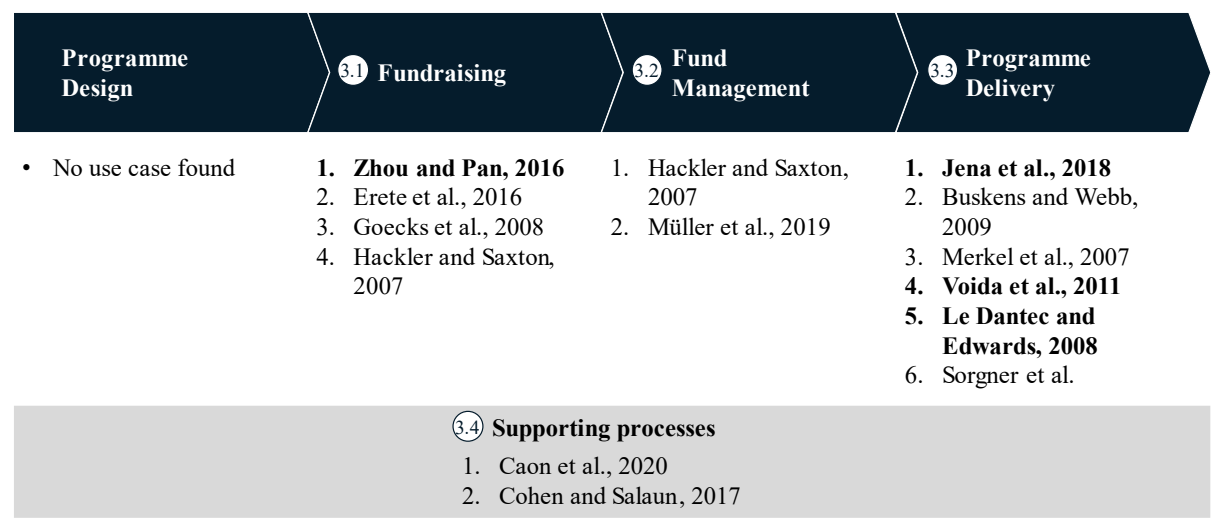

Figure 2. Use cases along the NGO value chain - lightweight IT use cases in bold

\subsection{Fundraising}

Of the four use cases identified for Fundraising, three classify as heavyweight IT and only one as lightweight IT. We present these in the following:

1. Social media. Using social media to report on solidarity objectives, engage existing and potential donors, expand visibility, improve organizational legitimacy, and increase the number of donors that finance the organization's endeavors (Zhou and Pan 2016). This use case could be classified as lightweight IT, as social media tools are provided directly by vendors. Usually, content is created and/or curated by the marketing departments - so IT departments are probably, in most cases, not even involved. Interestingly Social Media use appears to be the most commonly researched type of technology use in NGOs in recent years - probably due to the easy availability of data. For example, some studies look at the use of one specific social media outlet like Twitter use for advocacy purposes (Halpin et al. 2020) or Facebook for Christian congregations (Lee 2018). Other studies look at more general characteristics like how organizational characteristics influence social media use in general (Seo and Vu 2020) or how offline measures can complement social media (Lai and Fu 2021).

2. Online open data portal. An open data portal to develop narratives to build a case for support from grantors and other stakeholders (Erete et al. 2016) probably needs to be classified as neither lightweight nor heavyweight IT. The participating NGOs only engaged in data manipulation practices that are not mentioned as activities relevant for ICT jobs under the ILOs International Standard Classification of Occupations used, for 
IADIS International Journal on Computer Science and Information Systems

example, by Eurostat (Eurostat 2020) and therefore considered as the relevant standard here (ILO 2012). The provision of the online data portal available at the research center's website and curated through a CMS system in the backend can be classified as heavyweight IT. The publication explicitly mentions developers on the side of the research center, and the integration of 16 different datasets is most likely a backend task (Erete et al. 2016).

3. Web pages. NGOs use web pages for communicating information about the NGO, helping potential donors discover NGOs, enabling donations, direct giving, individual and community advocacy, and helping NGOs learn about technology (Goecks et al. 2008). This technology use falls under heavyweight. It requires specialized web developers inside the organization, and the ILO occupation classification explicitly recognizes web developers as an ICT job (ILO 2012).

4. E-mail and online bulletin boards. External communication via e-mail or online bulletin boards and donor assistance as described in the publication - with e-mail servers run by the NGO itself (Hackler and Saxton 2007) would have to be classified as heavyweight IT. But the use of publicly available e-mail services like Gmail, Gmx, or Yahoo Mail, as some smaller NGOs do, would classify as lightweight IT.

\subsection{Fund Management}

As Fund Management pertains mostly to internal operations, a lack of publications on this topic in ICT use might be due to a reservation of NGOs to make this public. The two use cases found both detail heavyweight systems:

1. Enterprise Resource Planning (ERP) system. The introduction of an ERP system supports administrative and financial processes to manage internal employees and learners in a vocational programme (Miranda et al. 2016). ERP systems are mentioned as core examples by Bygstad (2017) for heavyweight systems due to their complex nature and specialized IT requirements.

2. Internal service portal or platform. Another case described in the literature is the introduction and use of internal service portals and platforms in a social welfare work organization. This solution provided a holistic framework for different applications and services (Müller et al. 2019). It can only be classified as a heavyweight system as it was also fully integrated with existing systems. Despite that, Müller et al. (2019) also discuss the introduction of mobile elements and the central platform, which could be classified as lightweight but would depend on the exact platform setup (Bygstad 2017).

\subsection{Programme Delivery}

Most interesting as directly connected to the NGOs cause and their work on the ground is the ICT use in Programme Delivery. Of the six use cases presented, three classify as heavyweight IT and three as lightweight IT:

1. WhatsApp communication. The researchers discuss education and communication with participants of programs through ICT use to provide visual material for farming best practices and connecting participants through WhatsApp (Jena et al. 2018). Such mobile technologies that do not require heavyweight backend systems fall under lightweight IT. 
2. Rural ICT access centers. NGOs can also apply ICT to empower participants in their ICT use - for example, empowering women and girls to use digital technologies to improve their outlook on the job market. As this focuses largely on using internet services that do not require specialized IT skills (Golzard 2019), this would be neither lightweight nor heavyweight IT. But the complimentary examples of rural access centers in this context would have to be classified as heavyweight IT, as they require IT specialists to run (Buskens and Webb 2009).

3. Websites for volunteer recruitment. Some case studies also discuss the ICT use concerning volunteers: A case study described volunteer recruitment as possible technology use. Even so, The researchers did not mention the explicit solution for the use case. The rest of the publication focused on website use. The specific example was an HTML-based website that could not be maintained by a non IT knowledgeable volunteer (Merkel et al. 2007). So this use case would have to be classified as heavyweight. But solutions like WordPress, where users do not need specific skills and get their IT managed by the vendor, would again classify as lightweight.

4. Management databases. A second example would be management that requires the use of a database (Voida et al. 2011). The discussed solutions - excel spreadsheets and web-enabled databases - would have to be classified as lightweight. They use readily available tools without any specific adaptations or add-ons for the context.

5. Service tracking databases. Such databases can also be relevant in managing client information and tracking services provided. One example of this is the pathways solution for homeless shelters in the US (Le Dantec and Edwards 2008). This solution could be considered lightweight as it appears to vendor-managed and to require minimal IT-related efforts by the personnel.

6. Digital platform for angel investment. When it comes to donor interaction with the programmes, some models directly involve donors in the programme activities, i.e., through digital platforms to facilitate angel investment in small businesses (Sorgner et al.). The example would fall under heavyweight IT as assessing programmes effectiveness often requires ERP-like programmes, and an investment platform is not only a frontend system.

\subsection{Supporting Processes}

For supply chain management research mentions one heavyweight and one lightweight use case:

1. Supply chain management. Managing health equipment in a crisis like the refugee crisis in Lebanon by tracking the stocks and their consumption at the last mile of the supply chain (Caon et al. 2020): From the description, the rather technically advanced health equipment inventory-management system shows similarities to an ERP system and therefore falls under heavyweight IT.

2. Digital cash transfers. In contrast, digital cash transfers as part of help programs only use existing externally managed digital technologies (Cohen and Salaun 2017). Therefore, it could fall under lightweight IT.

At the intersection of Human Resource Management and Information Technology, the literature mentions staff qualifications and their affinity to IT - mostly concentrated on the medical staff, teachers, and social scientists (Fafchamps et al. 2005). Staff qualifications are interesting in lightweight and heavyweight IT. The two knowledge regimes require different 
capabilities, and the user-driven lightweight IT also requires the users on the programme and fundraising sides to acquire minimum capabilities (Lacity and Willcocks 2016; Bygstad 2017). The topic of staff qualification also holds the potential for further research on IT-affinity research of certain stakeholder groups (Niehaves and Plattfaut 2011).

\subsection{Lightweight IT in the Social Sector - The Example of RPA}

One of the lightweight technologies that are of increased importance in the private sector is robotic process automation (RPA), with its potential to automate processes without changing the underlying (legacy) systems (van der Aalst et al. 2018). As the most current literature review shows, there is already a significant knowledge base (Hofmann et al. 2020). The current research also reflects that more and more firms experiment with RPA and what they learn in these endeavors. Significant is, for example, the use cases by Lacity and Willcox that explicitly document the learnings when introducing RPA (Lacity et al. 2017; Lacity and Willcocks 2016). RPA use cases like answering customer requests (Lacity and Willcocks 2016), automating accounting processes (Kokina and Blanchette 2019), or issuing payment receipts (Aguirre and Rodriguez 2017) should be easily transferable to NGOs. Fundraising could be easier if part of the donor interaction can be automated, i.e., by automatically providing a donation receipt when requested. Fund management could be easier if accounting processes are automated, i.e., if a central repository automatically pools data from different systems and employees do not manually integrate data from excel sheets. And Programme Delivery would be easier if background processes could be taken care of, i.e., by automatically providing information on a child's sponsorship on request. This solution would save costs, free up resources for more important tasks and even create new opportunities for broadening activities.

But in the current research on information technology use in NGOs, the focus of results and interpretations is still largely on heavyweight IT. RPA does not seem to appear. So far, there are only cases described in the healthcare and public sector, like, for example, automation in social services (Ranerup and Henriksen 2019) - nothing on NGOs or voluntary associations. There are, however, already vendor reports which support an optimistic outlook to the future adoption. UIPath, a prominent vendor of RPA solutions, for example, reports on a successful case of automating administrative processes for the New York Foundling (UiPath 2021). Nonetheless, NGO practitioners should be mindful of insights already gathered on RPA in other industries especially regarding governance questions - when introducing this new technology (see section 2).

\section{DISCUSSION, LIMITATIONS, AND OUTLOOK}

As figure 3 shows, the analysis of the 14 use cases implies that the focus of IT solutions supporting NGO value creation is still on heavyweight systems. We found evidence for lightweight IT in two out of four core activities. 


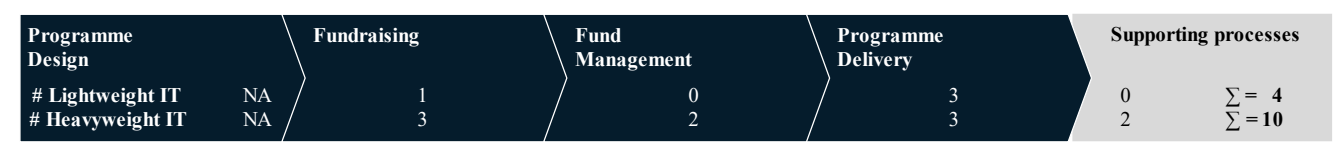

Figure 3. Lightweight and heavyweight use cases along the NGO value chain

As lightweight IT use cases are imaginable in all of these core activities, there is still some way to go. But those case studies that exist sound promising, and there are still way more use cases already established in the private sectors where lightweight technologies like, for example, RPA have shown significant benefits (Lacity et al. 2017).

However, readers need to treat these results with caution as we might be seeing a case of publication bias. The classical publication bias describes the effect that authors are more likely to publish positive than negative findings. This bias also affects funding and publishing opportunities as positive results are also seen more favorably by the research industry (Franco et al., 2014). Translated to ICT use in NGOs, this might mean that researchers are more likely to report on successful or sufficiently effectful technical innovations. On this basis, there are three possible reasons for our findings, which might overlap each other:

1. NGOs focus more on heavyweight IT and have not yet found the means and the opportunities to implement lightweight IT use cases.

2. Researchers are not reporting as many lightweight IT cases despite their existence because they suffer from a publication bias. Current use cases are not suitable for successful publications in established journals, e.g., because they are too small.

3. The research industry might not be sufficiently supportive of research in this sector and topic, e.g., funding might focus more on private-sector research, and NGO journals might not have a high IT affinity but rather focus on marketing and fundraising topics. Anecdotal evidence for the latter is the large number of publications on social media use even inside the body of knowledge dealing with NGOs and ICT and the number of publications labeled as public sector research instead of social sector research.

Nonetheless, this research effort contributes to theory and practice as it creates an overview, introduces the NGO value chain to research, and finally identifies possibly transferable solutions. Firstly, this research effort gave an overview of technology use cases along the NGO value chain. We can approximate that fewer than $1 / 3$ of use cases are already deploying lightweight IT solutions. The overview and classification should make it easier to transfer corresponding results from other disciplines and sectors. For example, practitioners do not need to invent lightweight IT governance anew, but they can adapt existing solutions from the private sector. This first step in the transfer should make this analytical lens available to researchers in the NGO context and enable practitioners to identify relevant literature to their daily challenges.

Secondly, the examples discussed in the context of the NGO value chain allow a more systematic analysis of use cases. Practitioners developed the NGO value chain (Snow et al. 2016). Therefore, research that follows these structures more closely should make it easier to synthesize knowledge and transfer it back into practice. Nonetheless, it could also benefit research that focuses on processes and possible IT support to build upon similar constructs to ensure transferability between research streams.

Finally, we could also show that certain lightweight solutions already successfully deployed in the private sector like RPA are not yet used in the NGO context or do not appear in the literature. Naturally, the transfer to the NGO context will not always be straightforward and simple, but the lightweight IT lens could offer a strategic opportunity and incite further research. 
IADIS International Journal on Computer Science and Information Systems

It could also help practitioners look more systematically for lightweight IT opportunities and empower the business side accordingly to create them. The latter would possibly require a change in IT strategies.

The utmost care went into the design of this research. Nonetheless, there are some limitations. The value chain used to order the use cases has not been peer-reviewed as no variant already discussed in research was available. Therefore, this research had to rely on the practitioner's perspective with the NGO reference model. The aim of the literature search was representative coverage. The chosen approach might not have achieved this aim due to the immense variety of keywords that research on the topic uses. As the classification could only build on the information presented in the case studies, it must remain an argument-based assumption.

Further detailed information might lead to a different classification. Several systems discussed in these case studies do not appear in the existing literature on lightweight IT. Therefore the classification is based on the authors' interpretation. Finally, future research should reflect these results with practice representatives to rule out possible publication bias effects.

These limitations, however, open avenues for further research around three main topics: Firstly, researchers should test the transferability of solutions systematically. This idea implies having an overview of relevant processes and available solutions or opportunities and prioritizing investments based on costs and impact. Such an evaluation should consider effectiveness, efficiency, and competitive/innovative potential aspects of the solution to make the best use of constrained resources (Ward 1994). It would be especially interesting to pursue practitioners' reports on successful lightweight IT implementation cases like the RPA implementation project of UiPath and the New York Foundling (UiPath 2021).

Secondly, a possible focus on lightweight IT in an NGO would have to be supplemented with the correct strategic approach regarding IT governance to tackle known issues like security and lack of integration (Bygstad 2017). There are several governance models available implying different levels of control for the IT department. It would depend on overall strategy and organizational goals, which one is most fitting (Bygstad and Iden 2017). One could imagine a laissez-faire approach by which local entities are allowed to develop their own lightweight IT solutions, leading to more IT knowledge in the organization outside of the NGOs IT department, and possibly very user-friendly solutions could also create inefficiencies and redundancies. Moreover, the current non-usage of lightweight IT could be driven by cognitive biases about lightweight IT within the respective NGOs (Fleischmann et al. 2014)

Thirdly, researchers should question the focus on heavyweight IT in the social sector under the changed conditions postulated for lightweight IT. The concept of lightweight IT allows for a re-evaluation of some results and interpretations: "Obviously, without a minimum level of capacity in terms of IT hardware and software, an organization will not be able to use IT for any meaningful administrative function, much less a strategic function" (Hackler and Saxton 2007, p. 477). But there is no need for heavyweight IT to run lightweight IT (Bygstad 2017). And to go even one step further in today's world with its ubiquitous consumer technologies, a social sector organization can deploy IT towards its strategic goals without IT investments or specific skills. Especially for social sector organizations operating in the developing countries, the effect of higher penetration of mobile phones than computers in these countries and the subsequent focus on mobile services (Hatt et al. 2013) and researchers should also evaluate the benefits of IT consumerization (Niehaves et al. 2012) further in the context of lightweight IT. 


\section{REFERENCES}

Aguirre, S.; Rodriguez, A. (2017): Automation of a Business Process Using Robotic Process Automation (RPA): A Case Study: Springer International Publishing (742).

Burkart, C.; Wakolbinger, T.; Toyasaki, F. (2018): Funds allocation in NPOs: the role of administrative cost ratios. In Central European Journal of Operations Research 26 (2), pp. 307-330.

Buskens, I.; Webb, A. (Eds.) (2009): African women and ICTs. London: Zed Books.

Bygstad, B. (2015): The coming of lightweight IT. In: European Conference on Information Systems (ECIS) Proceedings. Münster, Germany.

Bygstad, B. (2017): Generative Innovation: A Comparison of Lightweight and Heavyweight IT. In Journal of Information Technology, 32(2), pp. 180-193.

Bygstad, B.; Iden, J. (2017): A Governance Model for Managing Lightweight IT. In Á. Rocha, A. Correia, H. Adeli, L. Reis, S. Costanzo (Eds.): Recent Advances in Information Systems and Technologies. WorldCat. 569 volumes (Advances in Intelligent Systems and Computing), pp. 384-393.

Canon, M.; Khaled, O. A.; Vaucher, P.; Mezher, D.; Mc Guire, G. (2020): Digitalization of the Last Mile of a Humanitarian Supply Chain. In Ahram T., Taiar R., Gremeaux-Bader V., Aminian K. (Ed.): Human Interaction, Emerging Technologies and Future Applications II. IHIET 2020: Springer, Cham (Advances in Intelligent Systems and Computing, 1152).

Cohen, L.; Salaun, V. (2017): E-Cash \& E-Vouchers: The digitalization of the humanitarian aid and logistics. In W. Kersten, T. Blecker, C. M. Ringle (Eds.): Digitalization in Supply Chain Management and Logistics: Smart and Digital Solutions for an Industry 4.0 Environment. Proceedings of the Hamburg International Conference of Logistics (HICL). 23 volumes (23).

Crete, S.; Ryou, E.; Smith, G.; Fassett, Khristina M.; Duda, S. (2016): Storytelling with Data: Examining the Use of Data by Nonprofit Organizations. In: Proceedings of the 19th ACM Conference on Computer-Supported Cooperative Work \& Social Computing (CSCW '16). New York, USA: Association for Computing Machinery, pp. 1273-1283.

Eurostat (2020): Employment by occupation and economic activity (from 2008 onwards, NACE Rev. 2) $1000 . \quad$ Available online at http://appsso.eurostat.ec.europa.eu/nui/show.do?dataset=lfsa_eisn2\&lang=en, checked on 10/3/2020.

Fafchamps, M.; Owens, T.; Barr, A. (2005): The governance of non-governmental organizations in Uganda. In World Development.

Fleischmann, M.; Amirpur, M.; Benlian, A.; Hess, T. (2014): Cognitive Biases in Information Systems Research. A Scientometric Analysis. In: European Conference on Information Systems (ECIS) Proceedings. Tel Aviv, Israel.

Franco, Annie; Malhotra, Neil; Simonovits, Gabor (2014): Social science. Publication bias in the social sciences: Unlocking the file drawer. In Science 345 (6203), pp. 1502-1505. DOI: $10.1126 /$ science. 1255484

Goecks, J.; Voida, A.; Voida, S.; Mynatt, E. (2008): Charitable technologies: Opportunities for collaborative computing in nonprofit Fundraising. In: Proceedings of the ACM Conference on Computer Supported Cooperative Work, CSCW. San Diego, USA, pp. 689-698.

Golzard, V. (2019): Economic empowerment of Iranian women through the internet. In Gender in Management 35 (1), pp. 1-18.

Hackler, D.; Saxton, G. D. (2007): The Strategic Use of Information Technology by Nonprofit Organizations: Increasing Capacity and Untapped Potential. In Public Administration Review 67(3), pp. 474-487.

Haddad, A.; DeSouza, A.; Khare, A.; Lee, H. (2017): Examining potential benefits and challenges associated with the Internet of Things integration in supply chains. In Journal of Manufacturing Technology Management 28 (8), pp. 1055-1085. 
IADIS International Journal on Computer Science and Information Systems

Halpin, Darren R.; Fraussen, Bert; Ackland, Robert (2020): Which Audiences Engage with Advocacy Groups on Twitter? Explaining the Online Engagement of Elite, Peer, and Mass Audiences with Advocacy Groups. In Nonprofit and Voluntary Sector Quarterly, 089976402097981. doi: $10.1177 / 0899764020979818$

Harris, J.; Ives, B.; Junglas; I. (2012): IT Consumerization: When Gadgets Turn into Enterprise IT Tools. In MIS Quarterly Executive 11.

Hofmann, P.; Samp, C.; Urbach, N. (2020): Robotic process automation. In Electronic Markets 30, pp. 99-106.

ILO (2012): International standard classification of occupations. ISCO-08. Geneva (International standard classification of occupations). Available online at $\mathrm{http} / / /$ search.ebscohost.com/login.aspx?direct=true \&scope $=$ site \&db=nlebk\&db=nlabk\&AN=471696.

Jena, S.; Jena, A.; Swain, S. (2018): Development of Women through Digitalization in Odisha. In CPUHResearch Journal 3 (2), pp. 262-265.

Kokina, J.; Blanchette, S. (2019): Early evidence of digital labor in accounting: Innovation with Robotic Process Automation Author links open overlay panel. In International Journal of Accounting Information Systems 35.

Kotoba, M. (2017): Measuring Digitalization - Key Metrics. In Foundations of Management 9.

Lacity, M.; Willcocks, L.; Craig, A. (2017): Service Automations: Cognitive Virtual Agents at SEB Bank. In The Outsourcing Unit Working Research Paper Series.

Lacity, M.; Willcocks, L. P. (2016): Robotic Process Automation at Telefónica O2. In MIS Quarterly Executive 15 (1), pp. 21-35.

Lai, Chih-Hui; Fu, Jiawei Sophia (2021): Humanitarian Relief and Development Organizations' Stakeholder Targeting Communication on Social Media and Beyond. In Voluntas: International Journal of Voluntary and Nonprofit Organizations 32 (1), pp. 120-135.

Le Dantec, C. A.; Edwards, W. K. (2008): The View from the Trenches: Organization, Power, and Technology at Two Nonprofit Homeless Outreach Centers. In CSCW.

Lee, Young-Joo (2018): Is your church "liked" on Facebook? Social media use of Christian congregations in the United States. In Nonprofit Management and Leadership 28 (3), pp. 383-398. doi: $10.1002 / \mathrm{nml} .21291$.

Merkel, C.; Farooq, U.; Lu X., Craig G.; Rosson, M. B.; Carroll, J. M. (2007): Managing technology use and learning in nonprofit community organizations: methodological challenges and opportunities. In: In Proceedings of the 2007 symposium on Computer human interaction for the management of information technology (CHIMIT' 07). New York, USA: Association for Computing Machinery.

Miranda, M. Q.; Farias, J. S.; Schwartz, C. A.; Pascualote, J.; Almeida, L. (2016): Technology Adaption in Diffusion of Innovations Perspective: Introduction of an ERP System in a Non-Profit Organization. In RAI: Revista de Administração e Inovação 13 (1), pp. 48-57.

Müller, U.; Deelmann; T. (2019): Digitalization in Public Services: Process Automation and Workforce Management at BruderhausDiakonie, a Social Services Organization. In N. nUrbach, M. Röglinger (Eds.): Digitalization Cases. How Organizations Rethink Their Business for the Digital Age. Cham: Springer International Publishing (Management for professionals), pp. 313-327.

Niehaves, B.; Köffer, S.; Ortbach, K. (2012): IT Consumerization - A Theory and Practice Review. In: Americas Conference on Information Systems (AMCIS) Proceedings. Seattle, USA.

Niehaves, B.; Plattfaut, R. (2011): The MATH of Internet Adoption: Comparing Different Age-Groups. In Wirtschaftsinformatik Proceedings.

Øvrelid, E. (2018): Strategic shifts in digital infrastructures: Connecting discursive formations and lightweight IT. Series of dissertations submitted to the Faculty of Mathematics and Natural Sciences, University of Oslo No. 2016, Oslo.

Porter, M. E. (1985): The Competitive Advantage: Creating and Sustaining Superior Performance. NY, USA: Free Press. 


\section{LIGHTWEIGHT IT AS A NEW ANALYTICAL LENS FOR DIGITALIZATION OF NGOS}

Randrup, A.; Henriksen, H. Z. (2019): Value positions viewed through the lens of automated decisionmaking: The case of social services. In Government Information Quarterly 36 (4), p. 101377 DOI: $10.1016 /$ j.giq.2019.05.004 .

Seo, Hyunjin; Vu, Hong Tien (2020): Transnational Nonprofits' Social Media Use: A Survey of Communications Professionals and an Analysis of Organizational Characteristics. In Nonprofit and Voluntary Sector Quarterly 49 (4), pp. 849-870. DOI: 10.1177/0899764020908340 .

Snow, G.; Smith, M.; Stecher, K. (2016): NGO Reference Model. An enabler for digital transformation. Available online at https://www.ngoreferencemodel.org/.

Sorgner, A.; Bode, E.; Krieger-Boden, C.: Women 20 Study "The Effects of Digitalization on the Gender Equality in the G20 economies". With assistance of Urvashi Aneja, Susan Coleman, Vidisha Mishra, Alicia RobbMay. Kiel Institute for the World Economy. Kiel, Germany. Available online at https://www.emsdialogues.org/wp-content/uploads/2017/08/20170707_W20_Studie_v2.5.pdf.

UiPath (2021): Nonprofit, the New York Foundling, saves 100,000 hours in manual work annually with UiPath. Available online at https://www.uipath.com/resources/automation-case-studies/new-yorkfoundling-ngo-rpa, checked on 3/29/2021.

van der Aalst, W.M.P.; Bichler, M.; Heinzl, A. (2018): Robotic Process Automation. In Business \& Information Systems Engineering volume 60, pp. 269-272.

Voida, A.; Harmon, E.; Al-Ani, B. (2011): Homebrew databases: complexities of everyday information management in nonprofit organizations. In : Proceedings of the SIGCHI Conference on Human Factors in Computing Systems (CHI '11). New York, USA: Association for Computing Machinery.

vom Brocke, J.; Simons, A.; Riemer, K.; Niehaves, B.; Plattfaut, R.; Cleven, A. (2015): Standing on the Shoulders of Giants: Challenges and Recommendations of Literature Search in Information Systems Research. In Communications of the Association for Information Systems 37.

Ward, J. (1994): A portfolio approach to evaluating information systems investments and setting priorities. In L. Willcocks (Ed.): Information management. The evaluation of information systems investments. Boston, MA: Springer US, pp. 81-97.

Zhou, H.; Pan, Q. (2016): Information, Community, and Action on Sina-Weibo: How Chinese Philanthropic NGOs Use Social Media. In Voluntas 27, pp. 2433-2457. 